\title{
Structural characterization of an anti-gp120 RNA aptamer that neutralizes R5 strains of HIV-1
}

\author{
ANTU K. DEY, ${ }^{1,2}$ CARLA GRIFFITHS, ${ }^{1}$ SUSAN M. LEA, ${ }^{2}$ and WILLIAM JAMES ${ }^{1}$ \\ ${ }^{1}$ Sir William Dunn School of Pathology and ${ }^{2}$ Laboratory of Molecular Biophysics, Department of Biochemistry, \\ University of Oxford, Oxford, United Kingdom
}

\begin{abstract}
We recently described the isolation of 2 -fluoropyrimidine-substituted RNA aptamers that bind specifically to the surface

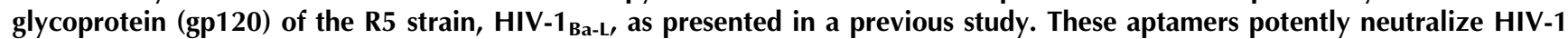
infectivity in human peripheral blood mononuclear cells of both tissue culture lab-adapted strains and diverse R5 clinical isolates from multiple clades. Here, we report a detailed structural characterization of one such neutralizing aptamer, B40, using enzymatic and chemical probing methods. We identify the minimal region of the aptamer essential for binding gp120 and accordingly design a 77-nucleotide truncated aptamer, B40t77. We then quantitatively analyze the binding affinity and neutralization potency of the parental and truncated (minimal) aptamer, and show them to be comparable. Furthermore, using results from secondary structure analysis, RNA mutagenesis and BIAcore surface plasmon resonance (SPR) binding assays, we hypothesize that a folded RNA structure is required to present specific nucleotide sequences to allow gp120-recognition and binding. The information gained from this study may provide leads for development of novel anti-HIV-1 therapies and can be used to extend our understanding of the molecular interactions between the virus and its host cell.
\end{abstract}

Keywords: aptamers; HIV-1; gp120; neutralization; RNA structure

\section{INTRODUCTION}

The human immunodeficiency viruses (HIV-1 and HIV-2) are the etiologic agents of acquired immunodeficiency syndrome (AIDS) (Barre-Sinoussi et al. 1983; Gallo et al. 1983, 1984) and are responsible for about three million deaths each year. Despite the development of potent inhibitors of critical viral enzymes and the combinatorial therapy approach, the goal of eradicating HIV infection remains elusive due to an unusual degree of interstrain diversity (Saag et al. 1988). Thus, there is a strong need to develop novel anti-retroviral agents. Classically, anti-retroviral agents have targeted viral enzymes but recent work demonstrates that agents targeted at disruption of virus entry into host cells may provide an effective alternate strategy (Moore and Doms 2003). HIV-1 enters $\mathrm{CD}^{+} \mathrm{T}$ cells by a series of molecular interactions between the viral envelope glycoprotein (Env) and primary cellular receptor (CD4) (Dalgleish et al. 1984) and a coreceptor (CCR5 or CXCR4) (Choe et al. 1996; Feng et al. 1996; Deng et al. 1997). The surface glycoprotein, gp120, first binds

Reprint requests to: William James, Sir William Dunn School of Pathology, University of Oxford, South Parks Road, Oxford OX1 3RE, United Kingdom; e-mail: william.james@pathology.oxford.ac.uk; fax: +44 (1865) 285756.

Article and publication are at http://www.rnajournal.org/cgi/doi/ 10.1261/rna.7205405. to CD4 and is thereby induced to undergo a conformational change facilitating the binding of the coreceptor (Sattentau and Moore 1991). This triggers further conformational changes in the transmembrane glycoprotein (gp41), leading to insertion of its $\mathrm{N}$-terminal fusion peptide into the target cell membrane and the final release of viral genome into host cytoplasm (Melikyan et al. 2000). Viral entry therefore presents a number of targets for therapeutic attack, both on the virus (gp120 and gp41) and the host target cell (CD4 and chemokine coreceptors). Considering the selective pressure imposed by antibodies $(\mathrm{Mr} \sim 150 \mathrm{kDa})$ driving the numerous evasion strategies that the virus utilizes to escape immune surveillance, we hypothesized that smaller ligands, such as aptamers (Mr typically $15-40 \mathrm{kDa}$ ), might be able to bind to the recessed, conserved regions on the envelope glycoprotein and block viral entry.

Aptamers are nucleic acid ligands derived from a complex combinatorial library by an in vitro evolution process, called SELEX (Ellington and Szostak 1990; Tuerk and Gold 1990). This method has been used to isolate a series of high-affinity 2'-fluoropyrimidine-substituted RNA aptamers that bind to gp120 of the CCR5-dependent HIV-1 strain, Ba-L (Khati et al. 2003). After the fifth round of selection using BIAcore, 25 distinct sequence families of anti-gp120 (Ba-L) aptamers were isolated that bound gp120 with high affinity (Khati et al. 2003). These aptamers neutralized HIV-1 $1_{\mathrm{Ba}-\mathrm{L}}$ infectivity in 
human peripheral blood mononuclear cells (PBMCs) by more than 1,000-fold. Importantly, they also neutralized diverse clinical isolates more efficiently than the neutralizing monoclonal antibodies tested (Khati et al. 2003). In this work, we report a complete enzymatic and chemical mapping of the secondary structural features of one neutralizing aptamer, B40, and determine the primary and secondary structural features essential for its full binding to gp120 by mutagenesis studies. The results indicate a minimal element comprising a three-way junction linking two helix-loops and a closing helix, with essential residues displayed mainly on the loops and junctional regions.

\section{RESULTS}

\section{Elucidation of secondary structure of aptamer B40}

In silico prediction of RNA secondary structure for B40 using several algorithms led to a small number of predicted, stable, folds. To determine whether any of these predicted structures could be experimentally confirmed we have used both enzymatic (S1, V1, or T1) and chemical probing methods. The patterns of sensitivities and protections seen in the enzymatic probing (Fig. 1) were found to confirm the most stable fold as predicted using several algorithms including mfold (version 3.1). This deduced secondary structure for the aptamer B40 is illustrated in Figure 1D. The structure can be divided into two domains. Domain I consists of nucleotides 1-76 and includes stem-loops 1, 2, and 3, while domain II consists of nucleotides 77-117 and includes stem-loop 4.

The chemical probing data also strongly supported this prediction - the only unexplained features of these data being the lack of reactivity of several nucleotides located in the interhelical regions. For example, A-39, 58, 80 and C-21, 33, 54 , and 55 did not show reactivity to DMS (Fig. 1E; Supplemental Fig. S2, at http://users.path.ox.ac.uk/ wjames/dey_ rna_205_supp.pdf). Similarly, G-25, 77, 84 and U-20, 24, 48 , and 49 were not reactive to CMCT (Fig. 1B,E). These discrepancies could arise due to tertiary interactions within the aptamer that affect DMS and CMCT reactivity or due the presence of alternative conformers. To estimate the degree of stability of the different helical domains, similar reactions with DMS and CMCT were also carried out under semidenaturing conditions (i.e., in presence of EDTA). U-68, 69, 74, 81, 87 and G-82, which did not react under native conditions with CMCT, melted under semi-denaturing conditions and showed reactivity to the same probe (Fig. 1B,E). We therefore propose that these residues are probably involved in weaker interactions within the helix, which denature under such conditions.

The possibility that the population of aptamer B40 molecules might contain a small proportion of a gp120-binding form folded alternately to that shown here is investigated genetically, in the context of deletion mutants, below.

\section{Determination of the gp120-binding site on the aptamer and binding affinity}

To determine the footprint of gp120 on aptamer B40, we compared the positions of nuclease cleavage in the presence and absence of protein. The footprinting data showed that binding of gp120 induced protection to varying degrees in domain I (Fig. 1A,D) in a concentration-dependent manner. The major protection involved a region encompassing $\mathrm{nt}$ 21-57 in domain I, indicating that the primary gp120-binding site on the 117-mer parent aptamer is present essentially in this domain. We also observed changes in sensitivity to RNase V1 and S1 after protein binding (Fig. 1A,D), implying protein-induced structural changes in the aptamer. Of the two domains, domain II was not implicated in gp120 binding. Helix 1 of domain I seemed to stabilize stem-loops 2 and 3. Taken together, these data led us to hypothesize that an

FIGURE 1. Enzymatic probing, RNA footprinting and solution structure of aptamer B40 and B40t77. (A) Autoradiogram of an 18\% polyacrylamide ( $8 \mathrm{M}$ Urea) gel, showing digestion products of $5^{\prime}$-end-labeled B40 with RNase T1, Nuclease V1 and S1 in the absence (0) and presence $(5,25 \mathrm{nM})$ of $\mathrm{HIV}-1_{\mathrm{Ba}-\mathrm{L}}$ gp120. A partial alkaline hydrolysate $\left(\mathrm{OH}^{-}\right)$and an RNase T1 digest ( $\mathrm{G}$ residue) ladder are run along side to facilitate alignment to known sequence. A vertical line marks the major gp120-protected region. The control $(C)$ corresponds to the $5^{\prime}$-endlabeled B40 aptamer incubated in presence of gp120 but without nucleases. The gaps in the alkaline hydrolysis $\left(\mathrm{OH}^{-}\right)$ladder are indicative of $2^{\prime}$-fluoropyrimidines. The wedges at the top of the gel indicate increasing concentrations $(0,5,25 \mathrm{nM})$ of gp120. (B) Secondary structure analysis of aptamer B40 using CMCT. Aptamer B40 was modified with CMCT and then reverse-transcribed using a $5^{\prime}$-end-labeled $3^{\prime}$-primer and AMV Reverse transcriptase. The cDNA products were then visualized by denaturing PAGE. The bands (shown by an arrow) indicate the position of the DMS modifications at residues that are unpaired in the native aptamer structure. Unmodified (Con) aptamer B40 was run in parallel to discriminate between stops specially induced by chemical modifications and those due to presence of stable secondary structures and false stops of AMV reverse transcriptase. N, modifications done under native conditions; SD, modifications done under semi-denaturing conditions (1 mM EDTA). Lanes $A, G, C, U$ represent a dideoxy RT sequencing ladder. The wedges at the top of the gel indicate increasing concentrations $(10 \mu m o l$ and $20 \mu \mathrm{mol})$ of CMCT. $(C, D)$ Proposed secondary structure of aptamer B40t77 and B40, respectively as deduced from the enzymatic probing data, which were used to constrain the mfold prediction algorithm. The residues targeted by RNase V1 (in green), nuclease S1 (in red) and the residues that become more sensitive to Nuclease V1 (green arrow) or S1 (red arrow) on gp120 binding are highlighted. The residues that show nuclease protection on binding to gp 120 are outlined and the thickness of the line indicates the degree of protection. The Watson-Crick base pairs are indicated by $\bullet$ whereas the Wobble G-U is indicated by O. (E) Reactivity of Watson-Crick positions in aptamer B40 toward DMS (N1-A and N3-C) and CMCT (N1-G and N3-U). Reactive under native (and also under semi-denaturing) conditions: DMS ( $\square$ ) and CMCT (O); unreactive under native conditions but reactive under semi-denaturing conditions: $\left(O^{*}\right)$. The Watson-Crick base pairs are indicated by a $\bullet$ whereas the Wobble G-U is indicated by a $:$ '. 


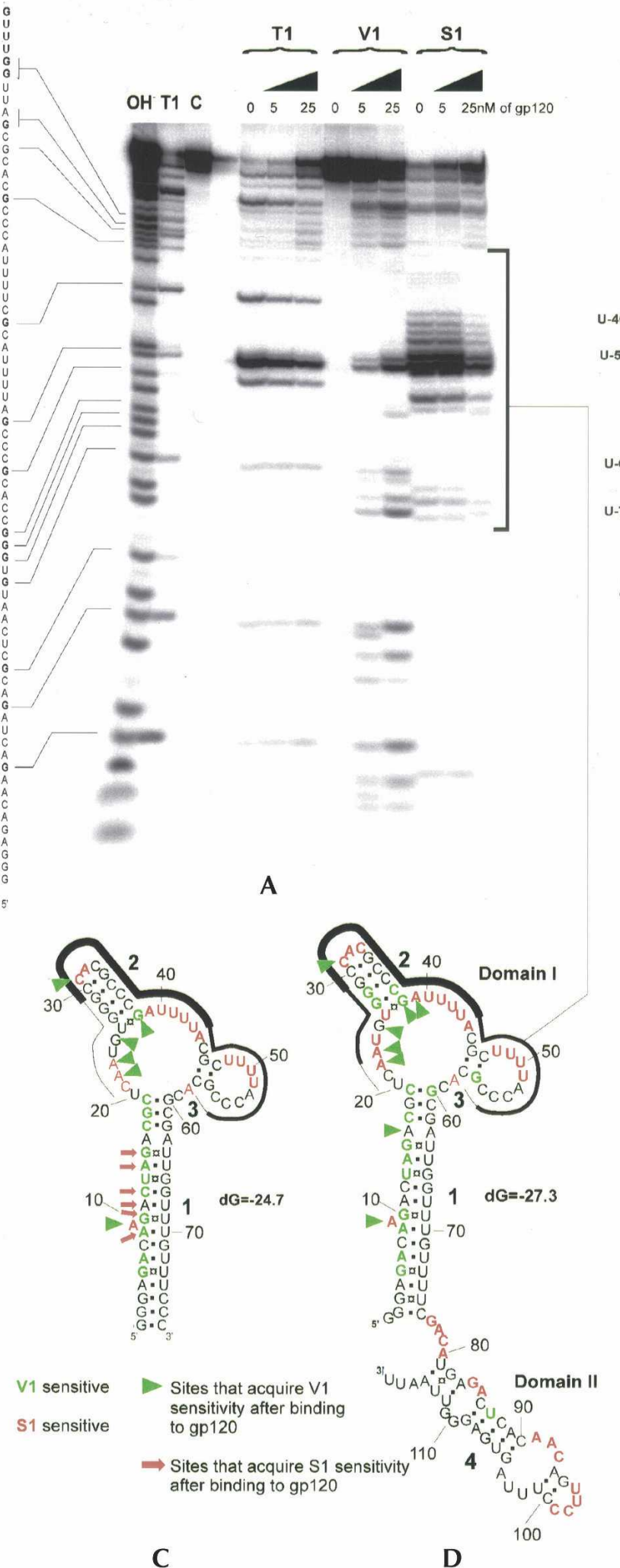

$\sum_{S D S D N N} \bar{\partial} U C G A$ 
aptamer comprising only of domain I would retain gp120binding activity. Accordingly, we constructed an aptamer, B40t77 ${ }_{(1-74 C C C)}$, which retained nt $1-74$ of domain I with two cytosines at the $3^{\prime}$-end to complete a 3-bp $5^{\prime}-3^{\prime}$ GC-clamp (Fig. 1C). This 77-nt truncated aptamer (referred to below as simply B40t77) retained its conformation (as domain I of parental aptamer) as deduced by the cleavage pattern of enzymatic probing and secondary structure predictions using mfold (Fig. 1C; Supplemental Fig. S1). The footprinting pattern in the truncated aptamer was similar to the parental aptamer B40 but a much stronger proteininduced structural change (unfolding) was observed in the former (Fig. 1C; Supplemental Fig. S1), especially in the helical stem 1 of domain I. This is plausible if domain II plays a role in stabilizing this region of domain I in the parent molecule, in the absence of protein.

In order to determine the binding affinities of the parent and the truncated aptamers, we performed a native gel mobility shift assay. Incubation of gp120 with the fulllength aptamer B40, (Fig. 2A,B) and truncated aptamer, B40t77, (Fig. 2D,E) yielded a complex of slower electrophoretic mobility at $\sim 50 \mathrm{nM}$ protein concentration compared with the free RNA. Three independent repeats of the experiment yielded estimates for the dissociation constant $\left(\mathrm{K}_{\mathrm{D}}\right)$ of $21 \pm 2 \mathrm{nM}$ for the parent aptamer (Fig. 2B) and $31 \pm 2 \mathrm{nM}$ for the truncated aptamer (Fig. 2E). From this it can be concluded that the truncated aptamer retains $\sim 90 \%$ of the binding energy of the parental aptamer and must therefore contain the majority of the elements required for productive binding.

We also investigated the binding of the aptamers B40 (Fig. 2C) and B40t77 (Fig. 2F) to immobilized gp120 on a CM5 sensor chip in real time using BIAcore SPR technology. A clear dose-dependent response was observed. However, the data could not be fitted using a 1:1 Langmuir binding or other simple model. We believe this is probably due to a low level of conformational heterogeneity in the aptamer to which the real-time binding is sensitive.

\section{Neutralization of an R5 strain (Ba-L) of HIV-1 by parental and truncated aptamers}

Earlier work has demonstrated that the majority of the HIV-1 $1_{\text {Ba-L }}$ gp120 directed aptamers (25 of 27), including B40, are able to neutralize homologous $\mathrm{HIV}_{-} \mathrm{B}_{\mathrm{Ba}-\mathrm{L}}$ in PBMCs (Khati et al. 2003). In this study we therefore wanted to determine whether the truncated aptamer was also able to prevent or limit the infectivity of this HIV-1 strain in target cells. Using an end-point dilution and p24antigen ELISA, we found that the truncated aptamer was as potent as the parental one in neutralizing homologous HIV- $1_{\text {Ba-L }}$ in human PBMCs (Fig. 3). At $300 \mathrm{nM}$, both aptamers neutralized HIV-1 $1_{\text {Ba-L }}$ entry to background level in contrast to no-aptamer and irrelevant aptamer controls, which had no effect on virus infectivity. Soluble human
CD4 also neutralized HIV-1 $1_{\mathrm{Ba}-\mathrm{L}}$ to near background level at $300 \mathrm{nM}$ concentration. A series of different concentrations were studied to derive the IC50 (the effective concentration of aptamer that inhibits $50 \%$ of viral infectivity) which was seen to be $\sim 2 \mathrm{nM}$ for both B40 aptamers (Fig. 3; similar data not shown). The 10 -fold difference between the $\mathrm{K}_{\mathrm{D}}$ and IC50 may simply reflect the very different natures of the assays used to determine the constants but may also be interpreted as implying that virus neutralization is achieved when substantially fewer than $50 \%$ of the gp120 sites present on the virus are bound by aptamer. It is plausible that only one gp120 unit in each spike trimer needs to be blocked in order to inhibit the formation of the corresponding hexameric, fusion-promoting complex of gp41 trimers. It would also seem that less than all of the spike trimers need to be functionally blocked in this way for fusion between the virus envelope and plasma membrane to be inhibited. However, our data do not permit one to make a precise calculation of the minimum proportion of trimers required for entry. A third interpretation is that the effective affinity is much higher in the context of intact virus due to high local concentration of gp120 target.

\section{Role of the modified 2'-fluoropyrimidines in the aptamer in ligand binding}

To investigate the potential role of the fluoropyrimidines in gp120 binding, we analyzed the gp120-binding abilities of aptamers in which either $2^{\prime}$-fluorocytosine or $2^{\prime}$-fluorouracil or both were replaced with their $2^{\prime}-\mathrm{OH}$ equivalents (Fig. 4). We found that aptamers in which $2^{\prime}$-F uridine was replaced with $2^{\prime}-\mathrm{OH}$ uridine, but which retained $2^{\prime}$-F-cytosine, retained gp120-binding ability. This indicates that none of the $2^{\prime}-\mathrm{F}$ groups in the relatively common uridines within the footprinted region is directly involved in binding gp120. On the other hand, those in which $2^{\prime}$-F-cytosine was replaced with $2^{\prime}-\mathrm{OH}$-cytosine, but which retained $2^{\prime}$-F-uridine, lost binding activity. This clearly indicates that one or more $2^{\prime}$-fluorocytosines is required for the interaction with gp120, but does not indicate whether the essential $2^{\prime}$ modification lies in a helix (e.g., helix 2) or loop (e.g., loop 2). Unsurprisingly, when both $2^{\prime}$-F-pyrimidines were replaced with the corresponding $2^{\prime}-\mathrm{OH}$-pyrimidine, binding was abolished.

\section{Analysis of sequence requirements within footprinted region}

It was possible that only a subset of nucleotides within the portion of aptamer B40 protected from nucleases by binding to gp120 were required for protein-nucleic acid interaction. In order to investigate this, we undertook a mutagenesis analysis of the region. Although more than 150 individual point mutants (and very many more multiple mutants) are theoretically possible within the footprinted region, we chose 


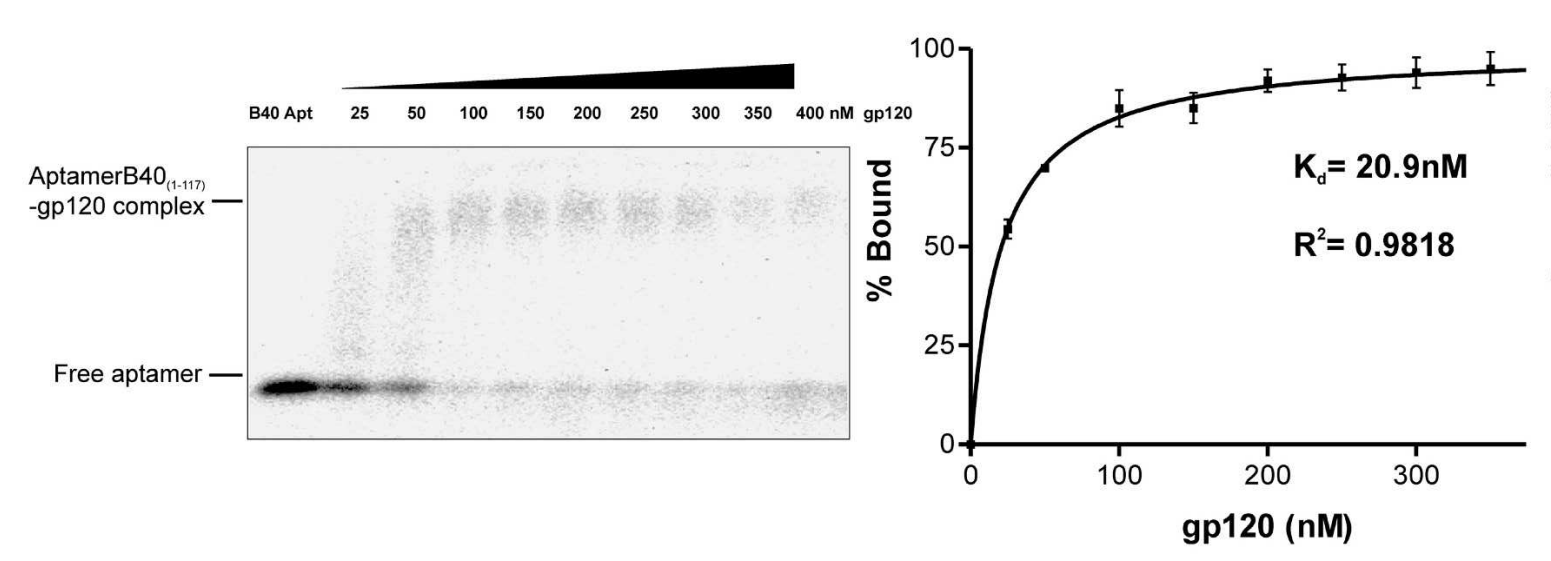

A

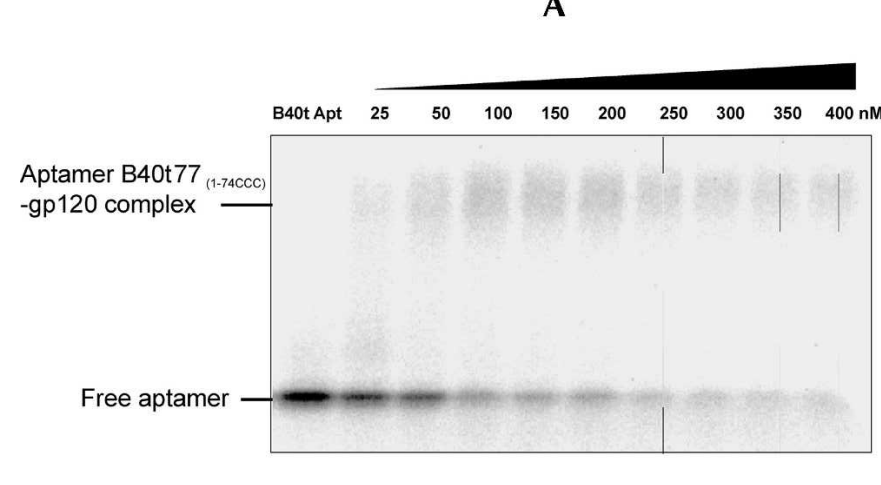

D
B

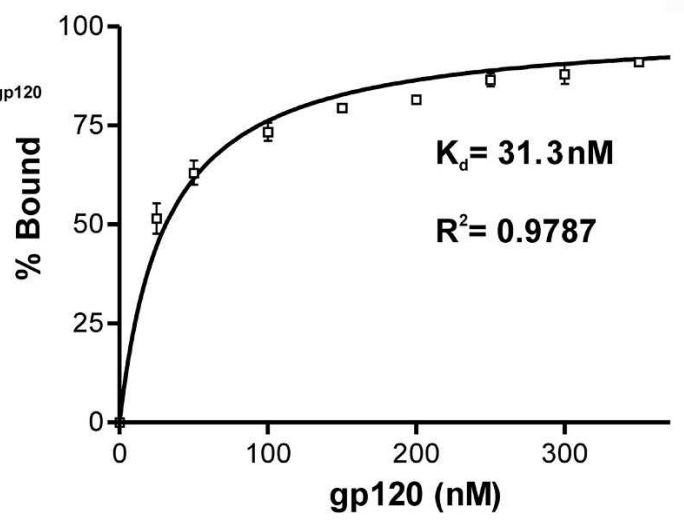

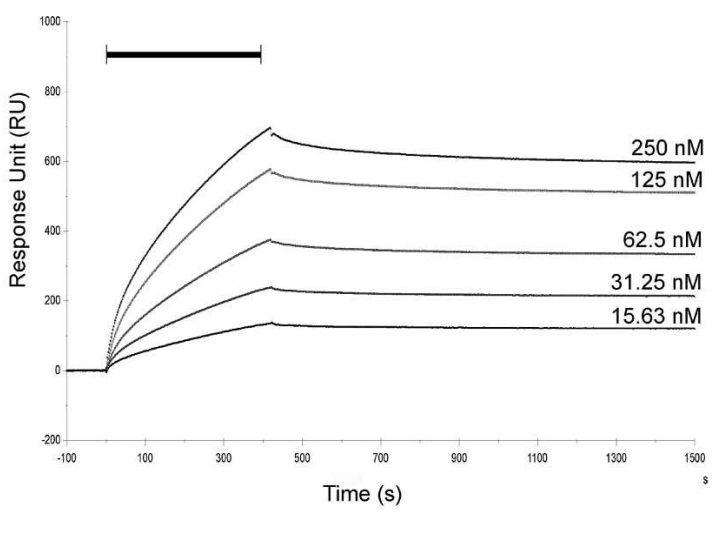

C

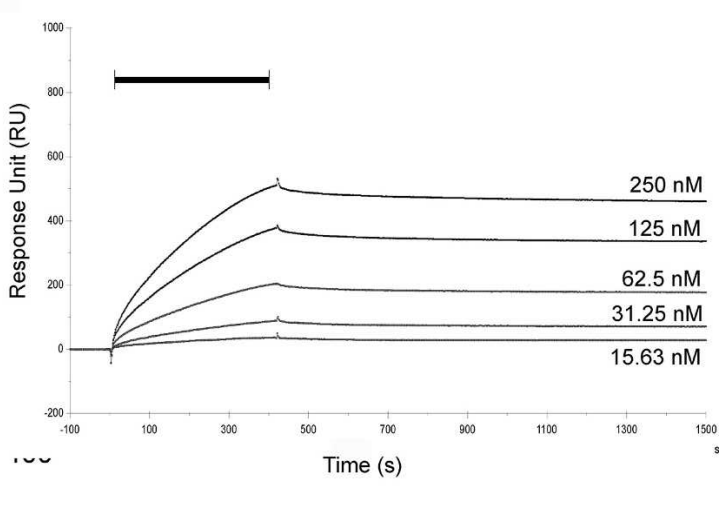

FIGURE 2. Gel mobility shift assay of the binding affinity of aptamer B40 and B40t77. (A,D) Autoradiogram of representative gels to analyze the binding affinity of aptamer B40 and B40t77 respectively using a range of increased protein concentration $(25$ to $400 \mathrm{nM}$ ) as assayed on a $1 \%$ agarose gel. (B,E) Representative plots of percentage of aptamer bound by gp120 as a function of protein concentration. The data were fitted to a hyperbolic function of nonlinear curve fitting method of Graph-Pad Prism. The titration yielded an equilibrium dissociation constant $\left(\mathrm{K}_{\mathrm{d}}\right)$ of $21 \pm 2 \mathrm{nM}$ and $31 \pm 2 \mathrm{nM}$ for the aptamer B40 and B40t77 respectively. (C,F) Dose-dependent binding of the aptamers B40 (C) and B40t77 (F) to immobilized gp120 on a CM5 sensor chip $(10,000 \mathrm{RU})$ using BIAcore surface plasmon resonance. The bar indicates the time during which the aptamers were flowed across the chip surface. 


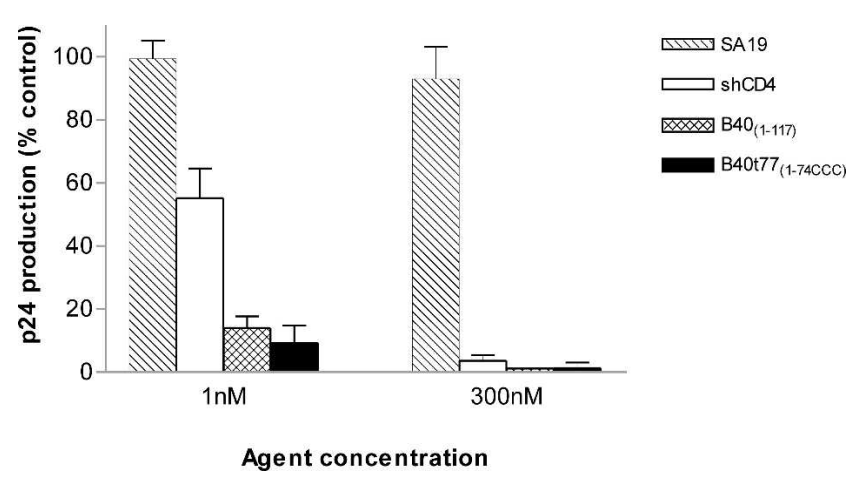

FIGURE 3. Neutralization of HIV-1Ba-L in human PBMCs by aptamers B40 and B40t77. The output of viral p24 antigen is used to measure the effectiveness of the aptamer using a p24 antigen ELISA. The extent of virus replication is represented as a percentage of p24 antigen produced in absence of any inhibitor. The soluble human CD4 (shCD4) is used as a positive control while aptamer SA19, raised against Streptavidin (Tahiri-Alaoui et al. 2002), is used as a negative control. The experiment is performed twice in triplicates, and the error bars represent the standard error of the mean.

initially to study a subset that was anticipated not to alter the secondary structure identified above, in order to obtain interpretable results. The majority of mutations of this type lay in the single-stranded loop and junction regions, and were identified following an exhaustive in silico analysis of possible mutations. Mutations in the residues in junction 1 resulted in significant loss of gp120 binding, indicating that they are required for interaction with gp120. The only mutation in this region that did not show a significant difference in gp120 binding is the substitution of C21A (Fig. 5). This is possible if the $5^{\prime}$ nucleotide of this sequence contributes very little to the free-energy change of gp120 binding of B40t77 aptamer. All mutants in the hairpin loops 1 and 2 showed near complete loss of binding, and as expected from footprinting data, these residues are also required for gp120 recognition and binding. All mutations in the region U40U43 (Junction $1^{\star}$ ) also resulted in significant loss of binding to gp120 (Fig. 5B). Generally multiple substitutions in this region (e.g., UUUU $\rightarrow$ CCCC) had more extreme effects than point mutations (e.g., U40A). Interestingly, although we have shown (above) that the $2^{\prime}-\mathrm{F}-\mathrm{U}$ can be replaced by $2^{\prime}-\mathrm{OH}-\mathrm{U}$ without loss of activity, these four uracils (irrespective of the 2 -ribose substituent) appear to be essential. Additionally, we analyzed double and quadruple mutants in helix 3 that were designed to preserve the native secondary structure. All mutants exhibited significant loss of binding as compared to the wild type B40t77 aptamer (Fig. 5). In sum, changes in most of the nucleotides within the footprinted region (junction 1 and $1^{\star}$, loops 1 and 2 and helix 3 ) result in loss of gp120 binding,

\section{Analysis of secondary structure requirements of gp120 binding}

Secondary structure modelling suggests that aptamer B40t77 ought, in principle, to be able to adopt a linear secondary
(A)

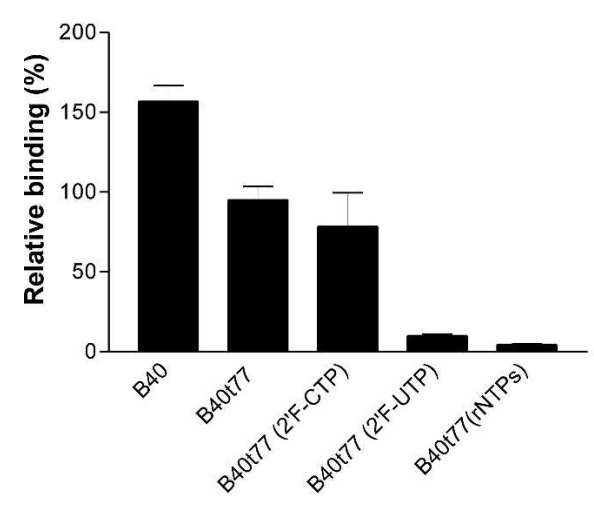

Aptamers (100 nM)
(B)

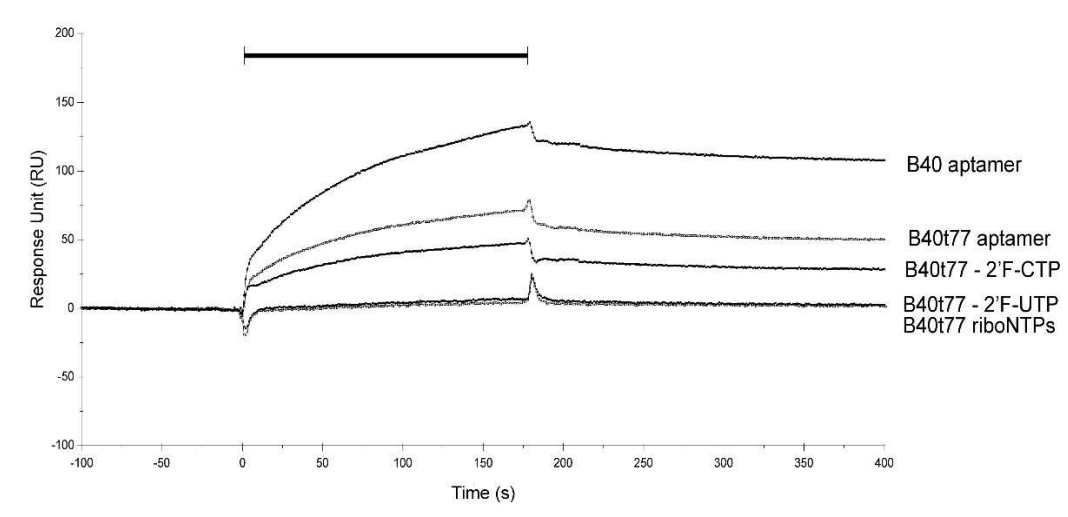

FIGURE 4. BIAcore binding assay to analyze the role of the modified $2^{\prime}$-fluoropyrimidines in the aptamer in ligand binding. (A) The relative binding score (RU) of aptamer $2^{\prime}$-fluoropyrimidines-substituted B40, and B40t77, 2'-fluorocytosine-substituted B40t77, 2'-fluorouracil substituted B40t77 and unsubstituted (containing ribonucleotides) B40t77 aptamer ( $\sim 100 \mathrm{nM})$ to immobilized gp120 (2500 RU) as assayed by BIAcore surface plasmon technology (SPR). The mean \pm SD of three independent experiments is plotted. The relative binding (RU) score is the binding value at $t=180 \mathrm{sec}$. Although $2^{\prime}$-fluoropyrimidine-substituted aptamers B40 and B40t77 bind to gp120 as expected, the $2^{\prime}$-fluorocytosinesubstituted B40t77 aptamer retains binding ability to gp120 while the $2^{\prime}$-fluorouracil-substituted B40t77 and unsubstituted B40t77 aptamer do not bind to the immobilized gp120. (B) Overlay of control corrected SPR curves to show representative binding of the said aptamers (one set of binding curves only). The thick bar indicates the time during which the aptamers were flowed across the chip surface. 


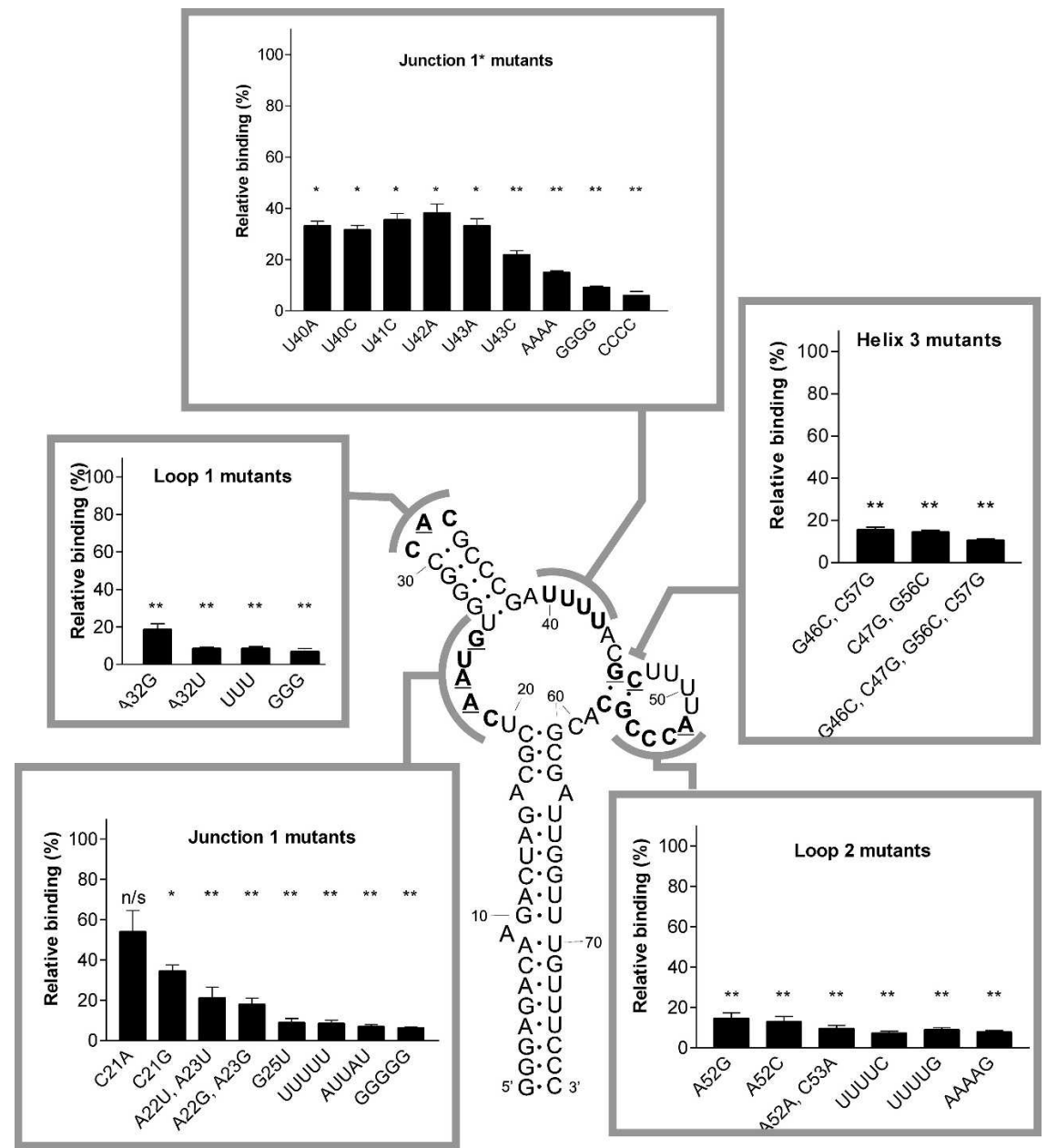

FIGURE 5. Analysis of sequence requirements within the gp120-footprinted region of aptamer B40t77. The sequence of truncated B40 is shown in the branched conformation revealed by secondary structure experiments above. Five portions of the structure that appeared to be protected from nuclease-mediated cleavage by binding to gp 120 are shown in bold, and those residues for which the clearest evidence exists for involvement in gp 120 binding are underlined. Mutations in the five regions were studied for their effect on gp120 binding using BIAcore SPR technology. The relative binding of all the mutants at $t=180 \mathrm{sec}$, compared to that of the wild-type B40t77 sequence, was scored using GraphPad prism and are shown as mean \pm SD and is the result obtained from three independent experiments. The relative binding (RU) score is the binding value at $t=180 \mathrm{sec}$. Values that were statistically indistinguishable from those of the wild type are indicated by $\mathrm{n} / \mathrm{s}$. Significant differences from the wild-type sequence are indicated with an $*(P<0.05)$, $* * \quad(P<0.01)$, or $* * *(P<0.001)$.

structure in addition to the branched structure supported by empirical evidence (see Fig. 6A). These two alternate structures are predicted to have similar stability to each other, and share several structural features in common. Consequently, it was possible that a minority of the aptamer population might adopt the linear form and escape biochemical detection and yet be responsible for the gp120-binding activity. To investigate this possibility, we turned once more to a genetic analysis. This was complicated by the fact that potentially discriminatory regions of secondary structure lay within the gp120-footprint and, consequently, primary sequence effects might confound secondary structure effects.
For example, point mutations in Helix 3 that disrupted the branched structure (G46C and C47G) resulted in loss of binding (see Fig. 6B) but compensatory mutations that restored structure failed to restore binding (see Fig. 5). Consequently, it is impossible to tell whether either the sequence or the secondary structure of this region, or both, are necessary for function.

Mutations in helix 1 that maintained its integrity $(\mathrm{G} 18 \mathrm{C}+\mathrm{C} 61 \mathrm{G}, \mathrm{A} 14 \mathrm{G}+\mathrm{U} 65 \mathrm{C}$, $\mathrm{C} 7 \mathrm{U}+\mathrm{G} 71 \mathrm{~A}$, and $\Delta \mathrm{A} 9)$ maintained gp120 binding (see Fig. 6C). However, they were all consistent with both the linear and branched forms, and so did not discriminate between the two forms.

A mutation in helix 1 that resulted in the loss of both branched and linear structures $(\Delta \mathrm{G} 18)$ resulted in a significant loss of binding. This mutant is predicted to adopt an abnormal, branched structure in which the Helix 3, Loop 2, and upper helix 1 are substantially distorted (see Fig. 6D). A compensatory deletion, that restored essentially normal branched and linear forms $(\Delta \mathrm{G} 18+\Delta \mathrm{C} 61)$ also restored gp120 binding. This clearly indicates that the maintenance of the secondary structure of aptamer B40t77 is required for gp120 binding, but does not clarify whether the binding form is the branched structure, the linear structure, or both.

Finally, we investigated mutations in helix 2 that were designed explicitly to discriminate between the two secondary structures. A mutation in helix 2 that prevented the formation of the branched structure, but was consistent with the linear structure (G27C) virtually abolished binding of aptamer to gp120 (see Fig. 6E). A compensating mutation that restored the branched structure, but abolished the linear structure $(\mathrm{G} 27 \mathrm{C}+\mathrm{C} 37 \mathrm{G})$ significantly restored gp120 binding $(P=0.0015, t$-test $)$ although not to full, wild-type levels. This result strongly supports the hypothesis that the three-way branched structure of the aptamer is the functional form, and shows that the linear alternate conformer, if indeed it coexists with the branched form in B40t77 populations, is not a ligand for gp120. However, the failure to completely restore gp120 binding following restoration of the branched form in the double mutant indicates that residues 27 and/or 37 also contribute slightly to binding in addition to their roles in stabilizing the overall structure. 
A

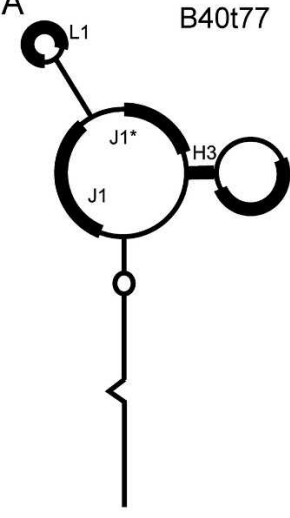
Branched form
$\Delta \mathrm{G}=-28.2 \mathrm{kcal} / \mathrm{mole}$

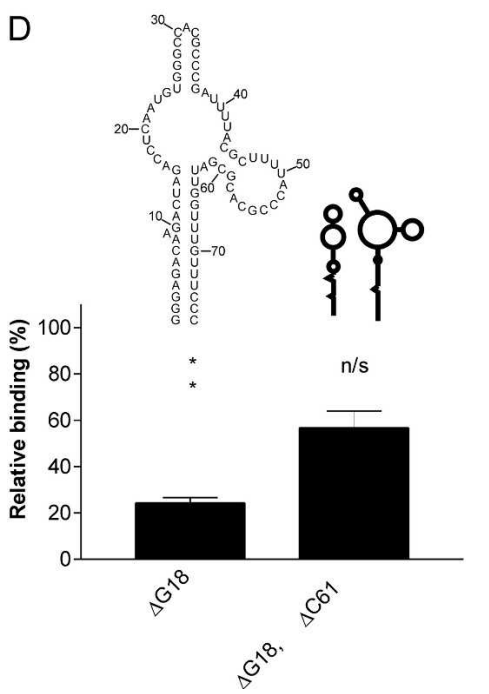

B

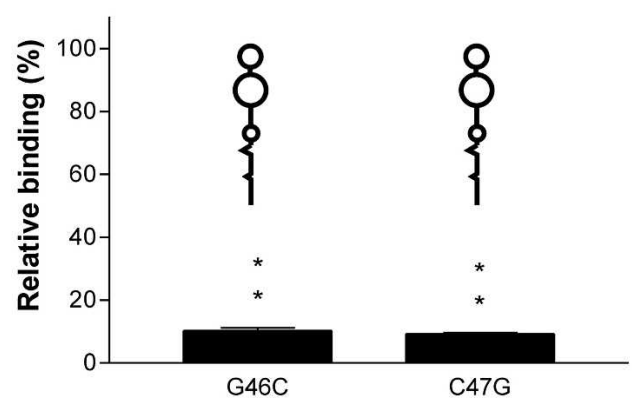

E
C

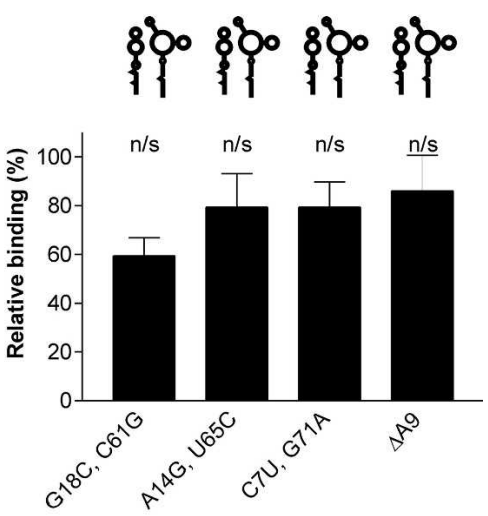

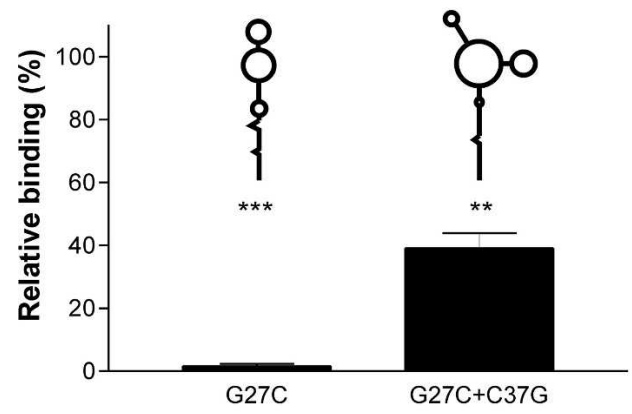

FIGURE 6. Analysis of secondary structure requirements for gp120 binding. (A) Graphical representation of the two potentially alternate conformers of B40t77. The regions identified as important for gp12 binding by footprinting analysis and mutagenesis, above, are labeled, and shown as thickened regions, to indicate their presentation in the alternate structures. $(B-E)$ Analysis of the effects of mutations on gp120 binding by BIAcore SPR analysis, as described in the legend to Figure 5. In each case, the conformer(s) predicted for each mutant are indicated by the cartoon immediately above the relevant data bar, except for panel $D$, mutant $\Delta \mathrm{G} 18$, for which the abnormal, branched structure predicted is shown in full. Significant differences from the wild-type sequence are indicated with an ${ }^{\star}(P<0.05),{ }^{\star *}(P<0.01)$, or ${ }^{\star * \star}(P<0.001)$.

\section{DISCUSSION}

We recently reported the neutralization of infectivity of diverse tissue-culture, laboratory-adapted (TCLA) and clinical CCR5tropic (R5) isolates of HIV-1 by aptamers raised explicitly against gp120 of the HIV-1 R5 strain Ba-L (Khati et al. 2003). Here we delineate the essential structural features of one such neutralizing aptamer, B40. By determining the secondary structure of the parent aptamer and the minimal region essential for full gp120 binding, we have been able to truncate the aptamer to a smaller size while preserving its binding and neutralizing properties. The more extensive contacts of the HIV gp120-binding aptamers here, and their consequently higher affinity, reflect the greater size of the target protein. The truncated aptamer B40t77 has a molecular weight of $\sim 23 \mathrm{kDa}$ : less than one-sixth the size of an IgG molecule and about one-half the size of the antigen binding fragment (Fab) of an antibody. We therefore believe that it should easily be able to access the deep, conserved regions in the "core" glycoprotein that larger entry inhibitors fail to access due to steric hindrance. This is further supported by recent findings by A.F. Labrijn and others (Labrijn et al. 2003), who clearly showed that the size of the CD4i-specific neutralizing agent is inversely correlated with its ability to neutralize primary HIV-1 isolates. Considering the nanomolar affinity of the parental and the truncated aptamer and their strong neutralizing potency, it is possible that the aptamer exerts its neutralizing effect either by occupying an essential receptor-binding site or by inducing nonproductive conformational changes in gp120. The aptamer may therefore serve as a tool to enable a better understanding of the molecular interactions between gp120 and its receptor on target cells. 
Nucleic acid-based therapeutic and diagnostic agents, besides binding to their target with high affinity and specificity, need to be nuclease-resistant and stable in biological fluids. The $2^{\prime}$-fluoro and $2^{\prime}$-amino modifications of RNA confer resistance to alkaline hydrolysis and ribonuclease degradation (Pieken et al. 1991). The results of the SPR binding analysis of the $2^{\prime}$-fluoro-modified and unmodified aptamer to gp120 (Fig. 4) indicate that the modifications at the $2^{\prime}$ position significantly affect the ligand-target interactions. The substitution of $2^{\prime}$-fluoropyrimidines with the $2^{\prime}-\mathrm{OH}$ group of pyrimidines resulted in complete loss of binding of the aptamer to gp120. This could be due to the ability of 2'-F RNA to form substantially stronger intramolecular helices that are more thermodynamically stable and form rigid structures more often than unmodified RNA (Pagratis et al. 1997), which bind to their target with higher affinity. The substitution of the $2^{\prime}$-F-cytidine with its ribonucleoside analog resulted in similar loss of binding, which could be attributed to the definite role of the fluorine atoms in the $2^{\prime}$ position of one or more cytidines in ligand binding. Besides, the substituents at the $2^{\prime}$ position also exhibit differences in their ability to form hydrogen bonds, which may account for the observed differences in binding. While the $2^{\prime}$-OH group of RNA can act as hydrogen-bond acceptor and donor, the $2^{\prime}-\mathrm{F}$ group can function only as probable weak hydrogen bond acceptor (Aurup et al. 1992). However, in each case, the contribution of a local conformational change in the oligonucleotide induced by the substitutions can also be an important factor in the loss or retention of the ligandbinding property of the aptamer. Therefore, it is possible that the selection performed with nucleic acid libraries with different $2^{\prime}$-moities can yield distinctly different families of aptamers with varying binding properties against the same or different targets.

The results of the mutagenesis study and SPR binding analysis strongly support RNA footprinting data and the secondary structure model presented above. Most mutations within the footprinted regions of the truncated aptamer significantly abrogated gp120 binding. Outside the footprinted region, mutations designed to specifically disrupt base-pairing within the RNA stems abrogated gp120 binding, whereas compensating mutations that restored the structure, or mutations that did not disrupt the structure, maintained gp120 binding. More importantly, a mutation within the footprinted helix 2 that disrupted the proposed, branched structure while stabilizing a linear, alternate conformer abolished binding, while a second, compensating mutation that restored the branched structure and abolished the linear, alternate conformer, significantly restored gp120 binding. This provides strong support for the hypothesis that a specific three-dimensional aptamer structure is required to present a small sequence-specific motif for gp120 binding. We note that sequences within the junctional portion of this structure become more sensitive to V1 nuclease following binding to gp120, indicating the possibility that the interaction indices a change in aptamer structure.
Intriguingly, although aptamers B4 and B116, which were also raised against $\mathrm{HIV}-1_{\mathrm{BaL}}$ gp120 and found to neutralize virus infectivity (Khati et al. 2003), appeared to be phylogenetically unrelated to aptamer B40 and showed no statistically significant relationship at the primary sequence level, it is possible that they share the structural motif described here for aptamer B40. Structural analysis indicates that they also comprise a three-way junction of two hairpin-loops and a terminal helix (data not shown). Moreover, they share fragmentary primary sequences in loop 1 (CAgC and CAaC compared with $\mathrm{CAC}$, in $\mathrm{B} 4, \mathrm{~B} 116$, and $\mathrm{B} 40$, respectively) and, possibly, loop 2 (motif ANNYG). Although this evidence is not conclusive, we think it possible that all three aptamers might share a fundamental structural motif that permits neutralizing binding to gp120. A high-resolution structure of the aptamer-gp120 complex will be able to further address this issue and reveal the multiple interactions that shape the overall gp120-recognition event.

\section{MATERIALS AND METHODS}

\section{Cells}

Spodoptera frugiperda Sf9s cells were kindly provided by John Sinclair (Laboratory of Molecular Biophysics, University of Oxford, UK). Human leukocytes were obtained from buffy coat fractions supplied by Bristol Hospital Services through the Oxford National Blood Services.

\section{Virus stock}

The HIV-1 $1_{\text {Ba-L }}$ strain used in this study was obtained through the AIDS Research and Reference Reagent program (Catalog no. 510), National Institute of Allergy and Infectious Diseases, National Institute of Health, Bethesda, MD.

\section{Oligonucleotides}

The oligonucleotides 1 and 2 were used as templates for the T7 transcription of the respective aptamers (listed $5^{\prime} \rightarrow 3^{\prime}$ ). The $5^{\prime}-$ and $3^{\prime}$-primers are listed and the T7 promoter is underlined.

1. Aptamer B40-TAATACGACTCACTATAGGGAGACAAGAC TAGACGCTCAaTGTGGGCCACGCCCGATTTTACGCTTTTA CCCGCACGCGATTGGTTTGTTTTCGACATGAGACTCACAA CAGTTCCCTTTAGTGAGGGTTAATT; $5^{\prime}$-primer (T3 SELEX)— AATTAACCCTCACTAAAGGGAACTGTTGTGAGTCTCATGT CGAA; and 3'-primer (T7 SELEX)—TAATACGACTCACTATA GGGAGACAAGACTAGACGCTC AA.

2. Aptamer B40t77-TAATACGACTCACTATAGGGAGACAAG ACTAGACGCTCAATGTGGGCCACGCCCGATTTTACGCTT TTACCCGCACGCGATTGGTTTGTTTCCC; 5'-primer-GGG AAACAAACCAATCGCG; and $3^{\prime}$-primer-TAATACGACTCA CTATAGGGAGACAAGACTAGACGC. 


\section{Expression of HIV-1 $\mathbf{1}_{\text {Ba-L }}$ gp120}

As described in Khati et al. (2003).

\section{In vitro transcription}

A total of $225 \mathrm{pmol}$ of DNA template was added to a final $500 \mu \mathrm{L}$ transcription reaction mixture composed of $40 \mathrm{mM}$ Tris-Cl (pH 7.5), 1 mM 2'F UTP, 1 mM 2'F CTP (Trilink BioTechnologies), $1 \mathrm{mM}$ ATP, $1 \mathrm{mM}$ GTP (Amersham Pharmacia), $6 \mathrm{mM} \mathrm{MgCl}_{2}$, $5 \mathrm{mM}$ dithiothreitol (DTT), $1 \mathrm{mM}$ Spermidine, and 1,500 $\mathrm{U}$ of T7 RNA polymerase (New England Biolabs) and incubated at $37^{\circ} \mathrm{C}$ for $16 \mathrm{~h}$.

The transcription was terminated by addition of $1 \mathrm{U}$ of RNasefree DNase I (Sigma) per $\mu \mathrm{g}$ of DNA template, and the reaction mixture was incubated at $37^{\circ} \mathrm{C}$ for $20 \mathrm{~min}$, followed by phenolchloroform extraction. The RNA was precipitated with ethanol, redissolved in water (Sigma), separated from low- $\mathrm{M}_{\mathrm{r}}$ contaminants with a Sephadex-G50 nick spin column (Amersham Pharmacia), and quantified by determination of $\mathrm{A}_{260}$. RNA was refolded by heating in water to $95^{\circ} \mathrm{C}$ for $3 \mathrm{~min}$ and then slow cooling to room temperature for $5 \mathrm{~min}$, then adjusted to $1 \times \mathrm{cHBS}$ buffer $(10 \mathrm{mM}$ HEPES, pH 7.4, $150 \mathrm{mM} \mathrm{NaCl}, 1 \mathrm{mM} \mathrm{CaCl}_{2}, 1 \mathrm{mM} \mathrm{MgCl}_{2}, 2.7 \mathrm{mM}$ $\mathrm{KCl}$ ) and further incubated at room temperature for $10 \mathrm{~min}$.

\section{${ }^{32} \mathbf{P} 5^{\prime}$-end labeling of RNA}

For $5^{\prime}$-end labeling, dephosphorylation of the terminal $5^{\prime}$ phosphate was carried out using bacterial alkaline phosphatase (New England Biolabs) and replaced with $\gamma$-phosphate from $\left[\gamma^{32} \mathrm{P}\right]-$ ATP using T4 polynucleotide kinase (Roche). The labeled RNAs were then electrophoresed on a $12 \%$ denaturing ( $8 \mathrm{M}$ urea) polyacrylamide gel and visualized by autoradiography, and recovered by passive elution from gel slices.

\section{Enzymatic probing and footprinting}

${ }^{32} \mathrm{P} 5^{\prime}$-end-labeled RNA was subjected to enzymatic digestion in $1 \times$ cHBS buffer in the presence of carrier RNA ( $1 \mu \mathrm{g}$ tRNA) at $20^{\circ} \mathrm{C}$ for 5 min with either RNase T1 (Amersham Pharmacia; $5 \times 10^{-3} \mathrm{U}$ ), Nuclease V1 (Pierce; $5 \times 10^{-3} \mathrm{U}$ ) or S1 (Amersham Pharmacia; $0.05 \mathrm{U})$. The reaction was stopped and the RNA was subjected to phenol/chloroform extraction and ethanol precipitation, then dissolved in formamide buffer. Footprinting was achieved by incubating similarly labeled aptamer with different concentrations of HIV- $1_{\text {Ba-L }}$ gp 120 for $1 \mathrm{~h}$ at $25^{\circ} \mathrm{C}$, followed by appropriate nuclease digestion. The digestion was terminated by phenol extraction, ethanol-precipitated, and dissolved in formamide buffer. The RNA fragments were then sized by electrophoresis on an $18 \%$ denaturing ( $8 \mathrm{M}$ Urea) polyacrylamide gel followed by autoradiography. Determination of the size of the fragments is facilitated by running a partial alkaline hydrolysis ladder (achieved by heating the labeled RNA in $50 \mathrm{mM} \mathrm{NaHCO}_{3}$, $\mathrm{pH} \mathrm{9.2,} \mathrm{at} 95^{\circ} \mathrm{C}$ for $10 \mathrm{~min}$ ) and a RNase T1-digest ladder (generated by digestion of 50,000 c.p.m [Cerenkov] denatured RNA at $55^{\circ} \mathrm{C}$ in $10 \mu \mathrm{L} 20 \mathrm{mM}$ sodium citrate, $1 \mathrm{mM}$ EDTA, $7 \mathrm{M}$ urea, $\mathrm{pH}$ 4.6) to indicate the position of the $\mathrm{G}$ residues.

\section{Chemical probing}

Chemical probing using Dimethyl sulphate (DMS; Fluka) and 1-cyclohexyl-3-(2-morpholinoethyl) carbodiimide metho- $p$-toluene sulfonate (CMCT; Sigma) was done as previously described (Peattie and Gilbert 1980; Ehresmann et al. 1987; Stern et al. 1988). DMS (modifies N1-A and N3-C) and CMCT (modifies N3-U, N1-G) modifications of $0.1 \mu \mathrm{g}$ of gel-purified and refolded aptamer B40 in presence of $2 \mu \mathrm{g}$ tRNA was carried out in $20 \mu \mathrm{L}$ reaction volumes. For DMS, the buffer contained $50 \mathrm{mM}$ Tris- $\mathrm{HCl}$ (pH 7.5), $5 \mathrm{mM}$ $\mathrm{MgCl}_{2}$, and $150 \mathrm{mM} \mathrm{KCl}, 5 \mathrm{mM} \beta$-mercaptoethanol while for CMCT, the buffer contained $50 \mathrm{mM}$ Borate- $\mathrm{NaOH}(\mathrm{pH} 8.0)$, $5 \mathrm{mM} \mathrm{Mg}\left(\mathrm{C}_{2} \mathrm{H}_{3} \mathrm{O}_{2}\right)_{2} \cdot \mathrm{H}_{2} \mathrm{O}, 150 \mathrm{mM} \mathrm{CH} \mathrm{CH}_{3} \mathrm{COOK}$ and $5 \mathrm{mM}$ $\beta$-mercaptoethanol. The semi-denaturing buffers contained $1 \mathrm{mM}$ EDTA. Reactions were performed at $20^{\circ} \mathrm{C}$ for $5 \mathrm{~min}$ in presence of $30 \mu \mathrm{mol}$ and $60 \mu \mathrm{mol}$ of DMS, for $20 \mathrm{~min}$ in the presence of $10 \mu \mathrm{mol}$ and $20 \mu \mathrm{mol}$ of CMCT. After ethanol precipitation, the modified RNAs were dissolved in water. A control, unmodified aptamer B40, was processed simultaneously.

\section{Primer extension}

Primer extension ( $\mathrm{Qu}$ et al. 1983) was carried out to detect the modified residues. Probed and control (unmodified) RNAs were hybridized to a $5^{\prime}-{ }^{32} \mathrm{P}$-labeled DNA primer $\left(5^{\prime}\right.$-AATTAACCCT CAC- $3^{\prime}$ ), which is complementary to the $3^{\prime}$-end of the target sequence, and the primer extended using AMV reverse transcriptase (Amersham pharmacia; $4 \mathrm{U}$ ). The cDNA patterns produced by primer extension of probed (and control) RNA were analyzed on an $8 \%$ denaturing ( $8 \mathrm{M}$ urea) polyacrylamide gel and autoradiographed. Sequencing reactions (Sanger et al. 1977) using dideoxy nucleotides and untreated RNA were carried out and run in parallel to facilitate the identification of modified residues. To detect the natural pause of reverse transcriptase during the primer elongation process, an elongation control of an unmodified RNA was also run in parallel.

\section{Secondary structure prediction of B40 aptamer}

The secondary structure model of aptamer B40 and B40t77 was deduced using mfold folding algorithm (Zuker 2003) and STAR software package (Gultyaev et al. 1995; van Batenburg et al. 1995). The predictions were constrained using data from enzymatic and chemical probing experiments.

\section{Gel mobility shift assay}

A native gel shift assay was used to quantify the dissociation constants for B40 and B40t77 aptamers binding to gp120. In a typical binding assay, $5^{\prime}$-end-labeled aptamer $(5000$ c.p.m. Cerenkov) in $1 \times$ cHBS buffer and $1 \mu \mathrm{g}$ tRNA was incubated in the presence of increasing amounts of gp120 for $1 \mathrm{~h}$ at room temperature. After incubation was complete, $3 \mu \mathrm{L}$ of loading solution containing $70 \%(\mathrm{v} / \mathrm{v})$ glycerol and $0.025 \%(\mathrm{w} / \mathrm{v})$ bromophenol blue was added to each reaction. The samples were then resolved on a $1 \%$ agarose gel. After the electrophoresis, the resolved samples on the gel were transferred onto a Hybond-N membrane (Amersham Pharmacia). The amount of aptamer in bound and unbound fractions was obtained using storage phosphor autoradiography and STORM phosphor imager (Molecular 
Dynamics). Dissociation constants of B40 and B40t77 aptamers were derived from a fit to the equation: Fraction bound $=B_{\max }$ $\left(\right.$ gp120)/([gp120] $\left.+K_{\mathrm{d}}\right)$, where $\mathrm{B}_{\max }$ represents the observed maximum fraction of aptamer bound, represents protein concentration and $K_{\mathrm{d}}$ is the dissociation constant. Due to diffusion of the aptamer-gp120 complex on the gel, the fraction of aptamer bound to gp120 was inferred from the fraction of free (unbound) aptamer (lane 1, Fig. 2, A and D).

\section{BIAcore surface plasmon resonance}

BIAcore 2000 was used to perform all the binding assays. Research grade CM5 sensor chips, NHS (N-Hydroxysuccinimide)/EDC (1-Ethyl-3-(3-dimethylaminopropyl) carbodiimide hydrochloride) coupling reagents, Ethanolamine and Glycine- $\mathrm{HCl}$ were from BIAcore AB. $1 \times$ cHBS buffer was degassed for $1 \mathrm{~h}$ and used as the running buffer. The flow rate was set to $5 \mu \mathrm{L} / \mathrm{min}$. Using amine-coupling chemistry, gp120 was immobilized onto CM5 sensor chip. The flow cells were activated for $10 \mathrm{~min}$ with a mixture of EDC $(0.2 \mathrm{M})$ and NHS $(0.05 \mathrm{M})$. Gp120 was buffer exchanged in $10 \mathrm{mM}$ sodium acetate $(\mathrm{pH} 5.2)$ and then injected at a concentration of $500 \mu \mathrm{g} / \mathrm{ml}$. For the dose-dependent binding assay, 10,000 RU, $5000 \mathrm{RU}$, and $1000 \mathrm{RU}$ were immobilized on three different flow cells while the fourth flow cell was used as a mock immobilized, blank control. In the binding assay to study the role of $2^{\prime}$-fluoropyrimidine modifications in the RNA, 2500 RU were immobilized. Following immobilization, ethanolamine (1M, pH 8.5) was injected for $10 \mathrm{~min}$ to block the remaining activated groups. Glycine- $\mathrm{HCl}(10 \mathrm{mM}, \mathrm{pH} 2.5)$ was then used to wash off any nonspecifically bound ligand. The aptamers were refolded in the binding buffer (as described above) and injected ( $35 \mu \mathrm{L}$ or $15 \mu \mathrm{L}$ ) over the flow cells at $5 \mu \mathrm{L} / \mathrm{min}$. Between the injections, the surfaces were regenerated by two $5-\mu \mathrm{L}$ injections of $10 \mathrm{mM} \mathrm{NaOH}$, following a $10 \mathrm{~min}$ wash with the running buffer. To correct for refractive index changes and instrument noise, the response data from the control surface were subtracted from the responses obtained from reaction surface using BIAevaluation 3.2.

\section{Cultivation of human PBMCs}

Human PBMCs were isolated by Ficoll-Hypaque (Amersham Pharmacia) density gradient centrifugation from heparinized buffy coats of normal, HIV-negative donors. The diluted, autologous plasma was saved, heat-inactivated, and clarified to provide autologous serum (AS) supplement for leukocyte culture. The PBMCs were washed six times in PBS (Sigma) at $4^{\circ} \mathrm{C}$ and were essentially free of platelets and granulocytes. In order to study HIV-1 neutralization, we used PBMC cultures cultivated without mitogen activation and interleukin-2 (IL-2). The cells were maintained in X-VIVO-10 (BioWhittaker) containing 2\% AS for $7 \mathrm{~d}$. The system without a mitogen and IL-2 produces a slowly proliferating mixed culture of lymphocytes and macrophages that in our hands supports a higher level of replication of viral isolates than mitogen-treated, cytokine-supplemented cultures. Following this, the cell cultures were used for infectivity and neutralization assays performed in 96-well plates.

\section{Neutralization assay}

Day-7 PBMCs seeded at $10^{5}$ cells/well were infected with $10^{3}$ infectious units $/ \mathrm{ml}$ of $\mathrm{HIV}-1_{\mathrm{Ba}-\mathrm{L}}$ in culture that had been preincubated with $50 \mu \mathrm{L}$ of serially diluted (half-log dilutions) antigp120 monoclonal aptamer or control aptamer, SA19, or soluble human CD4 for $30 \mathrm{~min}$ at room temperature. Aptamer SA19 was selected against Streptavidin by Tahiri-Alaoui et al. (2002) from the same SELEX library as B40. Three replicates were used at each dilution. At 16-hour post-infection, the medium-containing virus inoculum and aptamer was replaced with fresh medium and the cultures maintained for further $3 \mathrm{~d}$. The extent of virus replication was determined by measuring extracellular p24-antigen content from the supernatant as previously described (Moore et al. 1990; Simon et al. 1993).

\section{RNA mutagenesis and BIAcore binding analysis of the mutant B40t77 aptamers}

For the mutagenesis study, RNA mutants were first tested in silico using mfold so that they retain the three-way junction structure. Therefore, the mutant aptamers used in this study retain the said secondary structure, unless mentioned otherwise. The mutations (both substitutions or deletions) were introduced in the DNA template and the mutated oligos were obtained from SigmaAldrich. PCR amplification was done using the B40t77-specific $5^{\prime}$ - and $3^{\prime}$-primers. In vitro transcription was carried (as described above) to obtain the mutated B40t77 aptamers and the yield quantified by determination of $\mathrm{A}_{260}$. Binding was quantified using surface plamson resonance. Research-grade CM5 sensor chips were used and activated as described above. $2500 \mathrm{RU}$ of gp120 was immobilized on one flow cell via amine-coupling while a mock immobilized, blank flow cell was used as control. The aptamers were refolded in the binding buffer (as described above) and $15 \mu \mathrm{L}$ were injected over the flow cells at $5 \mu \mathrm{L} / \mathrm{min}$. Between the injections, the surfaces were regenerated as described above. Three independent experiments were performed and the samples were injected in random order in each case. The relative binding of all the mutants (after subtraction of the response from the control channel) was scored (at $t=180 \mathrm{sec}$ ) and the data are presented as mean \pm standard deviation of the response at that time point (Fig. 5).

\section{ACKNOWLEDGMENTS}

We thank Makobetsa Khati for technical advice during the neutralization assays, George Gao for provision of the original gp120 expression vector, and an anonymous reviewer for extremely constructive comments. This research was funded by the Wellcome Trust and A.K.D. was supported by Felix Scholarship. This work was also funded in part by the American Foundation for AIDS Research (AmFAR), grant no. 106603-36-RGGN.

\section{SUPPLEMENTAL DATA}

Supplementary material can be found at http://users.path.ox. ac.uk/ wjames/dey_rna_205_supp.pdf.

Received October 13, 2004; accepted March 18, 2005. 


\section{REFERENCES}

Aurup, H., Williams, D.M., and Eckstein, F. 1992. 2'-Fluoro- and $2^{\prime}$-amino-2'-deoxynucleoside $5^{\prime}$-triphosphates as substrates for T7 RNA polymerase. Biochemistry 31: 9636-9641.

Barre-Sinoussi, F., Chermann, J.C., Rey, F., Nugeyre, M.T., Chamaret, S., Gruest, J., Dauguet, C., Axler-Blin, C., Vezinet-Brun, F., Rouzioux, C., et al. 1983. Isolation of a T-lymphotropic retrovirus from a patient at risk for acquired immune deficiency syndrome (AIDS). Science 220: 868-871.

Choe, H., Farzan, M., Sun, Y., Sullivan, N., Rollins, B., Ponath, P.D., Wu, L., Mackay, C.R., LaRosa, G., Newman, W., et al. 1996. The $\beta$-chemokine receptors CCR3 and CCR5 facilitate infection by primary HIV-1 isolates. Cell 85: 1135-1148.

Dalgleish, A.G., Beverley, P.C., Clapham, P.R., Crawford, D.H., Greaves, M.F., and Weiss, R.A. 1984. The CD4 (T4) antigen is an essential component of the receptor for the AIDS retrovirus. Nature 312: 763-767.

Deng, H.K., Unutmaz, D., KewalRamani, V.N., and Littman, D.R. 1997. Expression cloning of new receptors used by simian and human immunodeficiency viruses. Nature 388: 296-300.

Ehresmann, C., Baudin, F., Mougel, M., Romby, P., Ebel, J.P., and Ehresmann, B. 1987. Probing the structure of RNAs in solution. Nucleic Acids Res. 15: 9109-9128.

Ellington, A.D. and Szostak, J.W. 1990. In vitro selection of RNA molecules that bind specific ligands. Nature 346: 818-822.

Feng, Y., Broder, C.C., Kennedy, P.E., and Berger, E.A. 1996. HIV-1 entry cofactor: Functional cDNA cloning of a seven-transmembrane, G protein-coupled receptor. Science 272: 872-877.

Gallo, R.C., Sarin, P.S., Gelmann, E.P., Robert-Guroff, M., Richardson, E., Kalyanaraman, V.S., Mann, D., Sidhu, G.D., Stahl, R.E., Zolla-Pazner, S., et al. 1983. Isolation of human T-cell leukemia virus in acquired immune deficiency syndrome (AIDS). Science 220: 865-867.

Gallo, R.C., Salahuddin, S.Z., Popovic, M., Shearer, G.M., Kaplan, M., Haynes, B.F., Palker, T.J., Redfield, R., Oleske, J., Safai, B. et al. 1984. Frequent detection and isolation of cytopathic retroviruses (HTLV-III) from patients with AIDS and at risk for AIDS. Science 224: 500-503.

Gultyaev, A.P., van Batenburg, F.H., and Pleij, C.W. 1995. The computer simulation of RNA folding pathways using a genetic algorithm. J. Mol. Biol. 250: 37-51.

Khati, M., Schuman, M., Ibrahim, J., Sattentau, Q., Gordon, S., and James, W. 2003. Neutralization of infectivity of diverse R5 clinical isolates of human immunodeficiency virus type 1 by gp120-binding $2^{\prime}$ F-RNA aptamers. J. Virol. 77: 12692-12698.

Labrijn, A.F., Poignard, P., Raja, A., Zwick, M.B., Delgado, K., Franti, M., Binley, J., Vivona, V., Grundner, C., Huang, C.C., et al. 2003. Access of antibody molecules to the conserved coreceptor binding site on glycoprotein gp120 is sterically restricted on primary human immunodeficiency virus type 1. J. Virol. 77: 10557-10565.

Melikyan, G.B., Markosyan, R.M., Hemmati, H., Delmedico, M.K., Lambert, D.M., and Cohen, F.S. 2000. Evidence that the transition of HIV-1 gp41 into a six-helix bundle, not the bundle configuration, induces membrane fusion. J. Cell Biol. 151: 413-423.

Moore, J.P. and Doms, R.W. 2003. The entry of entry inhibitors: A fusion of science and medicine. Proc. Natl. Acad. Sci. 100: 10598-10602.

Moore, J.P., McKeating, J.A., Jones, I.M., Stephens, P.E., Clements, G., Thomson, S., and Weiss, R.A. 1990. Characterization of recombinant gp120 and gp160 from HIV-1: Binding to monoclonal antibodies and soluble CD4. AIDS 4: 307-315.

Pagratis, N.C., Bell, C., Chang, Y.F., Jennings, S., Fitzwater, T., Jellinek, D., and Dang, C. 1997. Potent 2'-amino-, and 2'-fluoro-2'-deoxyribonucleotide RNA inhibitors of keratinocyte growth factor. Nat. Biotechnol. 15: 68-73.

Peattie, D.A. and Gilbert, W. 1980. Chemical probes for higher-order structure in RNA. Proc. Natl. Acad. Sci. 77: 4679-4682.

Pieken, W.A., Olsen, D.B., Benseler, F., Aurup, H., and Eckstein, F. 1991. Kinetic characterization of ribonuclease-resistant $2^{\prime}$-modified hammerhead ribozymes. Science 253: 314-317.

Qu, H.L., Michot, B., and Bachellerie, J.P. 1983. Improved methods for structure probing in large RNAs: A rapid "heterologous" sequencing approach is coupled to the direct mapping of nuclease accessible sites. Application to the $5^{\prime}$-terminal domain of eukaryotic 28S rRNA. Nucleic Acids Res. 11: 5903-5920.

Saag, M.S., Hahn, B.H., Gibbons, J., Li, Y., Parks, E.S., Parks, W.P., and Shaw, G.M. 1988. Extensive variation of human immunodeficiency virus type-1 in vivo. Nature 334: 440-444.

Sanger, F., Nicklen, S., and Coulson, A.R. 1977. DNA sequencing with chain-terminating inhibitors. Proc. Natl. Acad. Sci. 74: 5463-5467.

Sattentau, Q.J. and Moore, J.P. 1991. Conformational changes induced in the human immunodeficiency virus envelope glycoprotein by soluble CD4 binding. J. Exp. Med. 174: 407-415.

Simon, J.H., Somoza, C., Schockmel, G.A., Collin, M., Davis, S.J., Williams, A.F., and James, W. 1993. A rat CD4 mutant containing the gp120-binding site mediates human immunodeficiency virus type 1 infection. J. Exp. Med. 177: 949-954.

Stern, S., Moazed, D., and Noller, H.F. 1988. Structural analysis of RNA using chemical and enzymatic probing monitored by primer extension. Methods Enzymol. 164: 481-489.

Tahiri-Alaoui, A., Frigotto, L., Manville, N., Ibrahim, J., Romby, P., and James, W. 2002. High affinity nucleic acid aptamers for streptavidin incorporated into bi-specific capture ligands. Nucleic Acids Res. 30: http://nar.oupjournals.org/cgi/content/ full/30/10/e45.

Tuerk, C. and Gold, L. 1990. Systematic evolution of ligands by exponential enrichment: RNA ligands to bacteriophage T4 DNA polymerase. Science 249: 505-510.

van Batenburg, F.H., Gultyaev, A.P., and Pleij, C.W. 1995. An APLprogrammed genetic algorithm for the prediction of RNA secondary structure. J. Theor. Biol. 174: 269-280.

Zuker, M. 2003. Mfold Web server for nucleic acid folding and hybridization prediction. Nucleic Acids Res. 31: 3406-3415. 

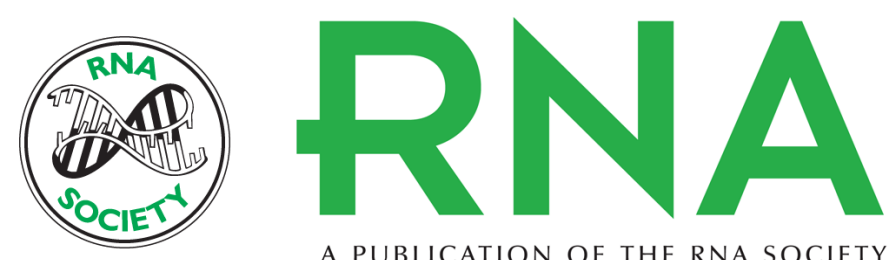

A PUBLICATION OF THE RNA SOCIETY

\section{Structural characterization of an anti-gp120 RNA aptamer that neutralizes R5 strains of HIV-1}

ANTU K. DEY, CARLA GRIFFITHS, SUSAN M. LEA, et al.

RNA 2005 11: 873-884

References This article cites 28 articles, 14 of which can be accessed free at: http://rnajournal.cshlp.org/content/11/6/873.full.html\#ref-list-1

License

Email Alerting Receive free email alerts when new articles cite this article - sign up in the box at the Service top right corner of the article or click here. 